\title{
CONSIDERAÇÕES ACERCA DAS QUESTÕES DE PARENTALIDADE FRENTE A SEPARAÇÃO CONJUGAL ${ }^{1}$ CONSIDERATIONS ABOUT PARENTALITY ISSUES IN CONJUGAL SEPARATION
}

\author{
Tatiane Pinto Rodrigues ${ }^{2}$ e Vanessa Antunes Alves ${ }^{3}$
}

\section{RESUMO}

O presente artigo foi extraído de um trabalho de conclusão de curso que teve como objetivo principal analisar e escutar uma criança que vivenciou a separação de seus pais, ou seja, foi disponibilizado espaço de fala para que ela conseguisse expressar o que sentiu com o anúncio dos pais acerca do divórcio dos mesmos. Foi realizado através de estudo de caso com 1 (uma) criança que se encontrou em atendimento em uma Clínica Escola do curso de Graduação em Psicologia na cidade de Santa Maria- RS. Tratou-se de um estudo de natureza descritivo-exploratório. Tornam-se objetivos desse estudo, compreender sobre as percepções de parentalidade diante da separação conjugal na visão de uma criança, verificar quais sentimentos foram gerados com a separação na criança, investigar qual o impacto frente a separação nas relações cotidianas da criança, e identificar se houveram modificações nas relações parentais após o divórcio, na visão de uma criança. O resultado encontrado mostrou que essa criança em específico aparentemente lida bem com o divórcio dos seus pais, porém destacou-se também que a comunicação é muito prejudicada entre os membros da família para situações do cotidiano, incluindo visita da criança ao pai, festas de aniversário, etc. É possível mencionar que o participante tornou-se resiliente quanto ao divórcio de seus pais, ou seja, além de ter uma percepção de mundo além da sua idade cronológica, é visível a sua maturidade quanto as novas configurações familiares, ou seja, a criança apresenta um bom entendimento quanto a decisão dos seus genitores.

Palvaras-chave: Conjugalidade; Divórcio; Família; Psicologia.

\section{ABSTRACT}

The present article was extracted from an end of course work that had as main objective to analyze and listen to a child who experienced the separation of their parents, that is, it was made available space for speech so that she could express what she felt with the announcement of the parents about their divorce. It was carried out through a case study with 1 (one) child that was being attended in a School Clinic of the Psychology Undergraduate course in the city of Santa Maria- RS. It was a descriptive-exploratory study. The objectives of this study were to understand the perceptions of parenting in the face of marital separation from a child's point of view, to verify which feelings were generated by the separation in the child, to investigate the impact of the separation on the child's daily relationships, and to identify whether there were changes in parental relationships after the divorce, from a child's point of view. The result found showed that this particular child apparently copes well with his parents' divorce, but it was also highlighted that communication is very impaired between family members for everyday situations, including the child's visit to the father, birthday parties, etc. It is possible to mention that the participant became resilient to his parents' divorce, that is, besides having a perception of the world beyond his chronological age, it is visible his maturity regarding the new family configurations, that is, the child presents a good understanding of his parents' decision.

Keywords: Conjugality; Divorce; Family; Psychology.

\section{Artigo.}

2 Autora, Orientadora, Professora e Coordenadora do curso de Psicologia da Faculdade Integrada de Santa Maria (FISMA). E-mail: tatiane.rodrigues@fisma.com.br

3 Coautora Psicóloga, graduada pela Faculdade Integrada de Santa Maria (FISMA). E-mail: alves.vanessapsi@gmail.com 


\section{INTRODUÇÃO}

A família representa um grupo social que desempenha marcada influência sobre a vida das pessoas, onde ela é encarada como um grupo que contém uma organização complexa, que é inserido em um contexto social muito mais amplo com o qual continua mantendo constante interação (BIASOLI-ALVES, 2004). Com isso, a família é vista como o primeiro sistema no qual um padrão de atividades, papéis e relações interpessoais são vivenciados pela pessoa em desenvolvimento no qual suas trocas darão base para o estudo do desenvolvimento do indivíduo (SIGOLO, 2004).

Dessa forma, é possível encontrar famílias seguindo modelos nucleares, casais dividindo os cuidados dos filhos e da organização familiar, mulheres e homens assumindo, independentes, o sustento da sua família -monoparentalidade-(OLIVEIRA et al., 2008; OLIVEIRA, 2009), uniões consensuais de parceiros separados ou divorciados (LOBO, 2009), casais sem filhos, casais homossexuais, casais com filhos adotivos, avós com netos, associações grupos de pessoas não consanguíneas, normalmente amigos, que moram juntos e uma grande variedade de formas a serem definidas (HINTZ, 2007).

Levando em consideração uma situação de divórcio, podemos dizer que o casal chega à decisão por inúmeros motivos: o desgaste do relacionamento, problemas financeiros, psicológicos, estado depressivo ou vício, a escolha insatisfeita do cônjuge, relacionamento extraconjugal, brigas constantes e até mesmo interferência dos familiares. A inclusão da mulher no mercado de trabalho também mudou muito a visão sobre o casamento, que nas décadas anteriores para a mulher o casamento era uma forma de sobrevivência (SANTOS, 2017).

Entende-se que após a decisão pelo divórcio, os ex-cônjuges podem precisar, em alguns casos, de muito tempo até que conquistem a estabilidade emocional. O tempo necessário para estabilizar as emoções dos ex-cônjuges é significativamente razoável para um adulto, no entanto, corresponde a uma parcela significativa da vida de uma criança (BRANDÃO, 2004). A separação dos pais sempre gera nos filhos perdas afetivas. Afinal, nasceram em um lar, recebiam cuidado, carinho e atenção do pai e da mãe de forma conjunta como uma unidade familiar. De um dia para outro um deles não está mais presente. As crianças podem não entender o que aconteceu, e muitas vezes sentirem culpa pelo fim da união. (DIAS, 2017).

Os filhos vão precisar consideravelmente dos pais durante o processo de separação. E é exatamente neste período que tanto o pai quanto a mãe estarão mais vulneráveis e frágeis, uma vez que há uma perda a ser elaborada e inúmeros sentimentos não são compreendidos, além de aspectos práticos a ser resolvidos (SCHABBEL, 2005). Portanto, os pais devem conversar com os filhos de uma maneira clara e honesta acerca das mudanças que virão a acontecer, pois a falta de informações pode suscitar fantasias e dificultar a superação do conflito (TRINDADE, 2011). 


\section{REFERENCIAL TEÓRICO}

\section{A SEPARAÇÃO CONJUGAL E O EXERCÍCIO DA PARENTALIDADE}

Há muito tempo, o divórcio deixou de ser um fenômeno que era exceção e se tornou um acontecimento quase cotidiano nas famílias. Desde a aprovação no Brasil em 1977, o número de divórcios teve um salto significativo, e cada vez mais casais buscam essa alternativa a fim de solucionar a insatisfação conjugal (GRZYBOWSKI, 2007). Entretanto, a questão se torna mais complexa quando na separação envolve a existência de filhos dessa união, e já não se trata mais apenas do fim de uma relação a dois que fracassou, mas também se dá início a uma relação de parentalidade de pais divorciados. Afinal, os filhos vão continuar precisando de cuidados (GRZYBOWSKI, 2010).

A parentalidade surge com a inclusão de um filho ao sistema familiar, onde exige do casal o desenvolvimento de novas tarefas, voltadas a proteção, ao sustento e a educação dos filhos, formando um novo subsistema, que é o subsistema parental. Os dois papéis, de pai e mãe são carregados de crenças, valores e comportamentos que são construídos consequentemente nas experiências com suas respectivas famílias de origem e com outros vínculos comunitários e sociais. Portanto, conjugalidade e parentalidade vão estar interligadas no processo de desenvolvimento familiar, sendo necessário que suas fronteiras sejam nítidas, para poder privilegiar as necessidades dos filhos não os inserindo aos conflitos e tensões de ordem conjugal (MINUCHIN et al., 2011; SILVA; LOPES, 2012; ZIVIANI, FÉRES-CARNEIRO; MAGALHÃES, 2012).

O fim da conjugalidade não vai decretar o fim da parentalidade. Ambos os pais vão continuar com todas as obrigações decorrentes do poder familiar. Caso ocorra o contrário, corre-se o risco de algum prejuízo ao direito de convivência familiar da criança, não em relação a um mau relacionamento entre um dos pais com o filho, mas sim do desentendimento que irá persistir entre seus responsáveis. A separação do casal não vai distinguir a relação parental da relação conjugal. A família parental não pode se dissolver. O filho passará a ter dois lares, mas a sua família de origem continua sendo uma só (DIAS, 2017).

Vemos com frequência na literatura que esta é uma das grandes dificuldades diante o divórcio: separar conjugalidade da parentalidade. A nova definição do envolvimento emocional dos dois indivíduos é um processo que leva tempo, que gera falhas nas fronteiras do relacionamento e nos conflitos pós-divórcio (HACKNER; WAGNER; GRZYBOWSKI, 2006). O que é bem frequente é que muitos pais e mães divorciados encontram dificuldades em manter um relacionamento coparental saudável, pois somados a todas as variáveis do contexto, ainda existe a questão do envolvimento materno e paterno após a separação. Pois a própria definição de coparentalidade, exige a presença de duas pessoas envolvidas e responsáveis pela educação dos filhos, e isto nem sempre ocorre (GRZYBOWSKI, 2010). 
O ideal é que mesmo apesar do divórcio ter ocorrido, os pais pudessem continuar assumindo funções educativas, participando das atividades do dia-a-dia dos seus filhos, promovendo o bem-estar, mas, é bem evidente a complexidade do fenômeno da parentalidade após a separação conjugal (CRISTIANE, 2010).

Para Krüger (2009) diante de uma situação de divórcio, os pais podem apresentar-se cheios de sofrimento, o que pode ou não gerar certa imobilização diante das necessidades dos filhos, envolvendo-os no conflito conjugal e, como consequência, descuidando-se das funções parentais. Ou seja, o sentimento de fracasso mediante o projeto de vida conjugal pode invadir as funções parentais impedindo que os ex-cônjuges atendam adequadamente seus filhos, imobilizando-se na dor e tornando-se impossibilitados de acessar os recursos necessários para a superação da crise. Por isso é importante considerar os filhos no contexto da separação conjugal, compreendendo as consequências para estes, as reorganizações que serão necessárias, suas vivências particulares a fim de subsidiar o entendimento da compreensão e das fantasias das crianças que estão envolvidas neste processo.

Mesmo que não formem mais um casal, pai e mãe deverão continuar a cumprir seu papel na família, que pode deixar de ser conjugal, mas nunca deixará de ser parental. Como consequência de suas escolhas pessoais e da autoridade que se achem no direito de exercer sobre os (as) seus (suas) filhos (as), cada pai e cada mãe estarão vinculados um ao outro pelos laços que os vinculam aos filhos em comum. No caso de divórcio, seguido de um novo casamento, os casais que têm filhos (as) possuem uma ligação para sempre (PONCIANO; CARNEIRO, 2017). Para Dantas (2004), é de grande importância que se fortaleçam os vínculos com os filhos após a separação. A autora salienta que a construção da personalidade da criança irá se relacionar com o momento no qual ela se reconhece em seus pais. A mesma levanta a importância paternal e maternal para o desenvolvimento sadio da criança, já que sem a relação com seus pais, a criança não irá conseguir construir sua própria identidade. Os momentos de ser reconhecido e se reconhecer precisam acontecer na relação entre pais e filhos.

Para Bolsoni-Silva (2009), a família pode contribuir de inúmeras formas para que as crianças não venham a sofrer com o divórcio, o autor cita a importância do diálogo e orientação realizada por um profissional durante tal processo, com o objetivo de minimizar os efeitos negativos da separação. A manutenção do diálogo entre os pais pode ajudar a criança a lidar com as dificuldades na transição da estrutura familiar. Se o filho encontrar nos pais uma fonte de apoio, ele pode até mesmo compartilhar seus medos e receios, onde seus pais irão ajudá-lo a suportar os mesmos. Pode-se dizer que os pais influenciam seus filhos, tanto pelo jeito como se comportam em relação a eles, quanto pela maneira como interagem com seus ex-cônjuges. Assim, salienta-se que o relacionamento entre os pais também precisa ser considerado quando se aborda a questão das visitas aos filhos e do seu bem-estar. O filho que é colocado no meio do fogo cruzado entre pai e mãe pode, em algum momento, ficar confuso por não saber de quem deve gostar e em qual dos dois pode confiar (DANTAS, 2004). 


\section{MATERIAL E MÉTODOS}

O presente relato de pesquisa que teve como objetivo disponibilizar espaço de fala para a criança que vivenciou a separação de seus pais foi desenvolvido através de estudo de caso (YIN, 2015). No estudo de caso, as análises e reflexões estarão presentes durante os vários estágios da pesquisa, especialmente quando o levantamento das informações, dados e evidências, em situações em que os resultados parciais sugeres alterações, correções de rumo. Em relação a sistematização e organização de rascunhos, notas de observações, transcrições, registro de comentários, diários, opiniões etc são agrupados em campo e anexados segundo algum critério definido no protocolo do estudo (MARTINS, 2008).

A presente pesquisa teve natureza descritivo-exploratória. A pesquisa descritiva, segundo Gil (2002), irá busca primordialmente a descrição de características de uma população ou fenômeno, ou o estabelecimento de relações entre variáveis, por meio da utilização de técnicas padronizadas de coleta de dados. Já a pesquisa exploratória tem por objetivo propiciar maior familiaridade com determinado tema, visando torná-lo mais explícito ou construir hipóteses, visando aperfeiçoamento de ideias ou a descoberta de intuições, e possibilita a consideração de diversos aspectos relativos ao fato estudado (GIL, 2002).

O estudo em questão partiu do pressuposto que a pesquisadora teve o compromisso ético com o participante envolvido na pesquisa, sendo assegurado a ele que teve acesso aos resultados da mesma, assim que ela se encontrou finalizada. Ressalta-se que o projeto atendeu integralmente a Resolução $\mathrm{n}^{\circ} 466$, de 12 de Dezembro de 2012, do Conselho Nacional de Saúde (CNS) que regulamenta a pesquisa com seres humanos, assim como a resolução nº16/2000 de 20 de Dezembro de 2000, do Conselho Federal de Psicologia. A resolução do CNS parte do pressuposto que o pesquisador tem o compromisso ético com os participantes envolvidos na pesquisa e que este deve ponderar entre riscos e benefícios individuais ou coletivos comprometendo-se com o máximo de benefícios e o mínimo de riscos e danos (BRASIL, 2012).

Para coleta de dados, esta pesquisa contou com uma ficha de dados sociodemográficos para a criança e um roteiro de entrevistas. Além dos procedimentos éticos que a pesquisa teve e sendo consentida pela mãe e a própria criança, a pesquisa foi gravada por áudio, para que em seguida, pudesse ser transcrita para manter o maior grau de fidedignidade com a pesquisa realizada. O convite foi realizado a partir de panfletos informando sobre a pesquisa nos corredores da Instituição, e após algum tempo, a estagiária fez o intermédio informando a pesquisadora sobre um menino que atendia aos requisitos da pesquisa, após isso já foi providenciado um primeiro contato com a mãe, para expor a pesquisa e assim avançar com a mesma. 
Dessa forma, foi realizada 1 entrevista com a mãe para explicar sobre a proposta da entrevista e sobre os termos, assinaturas e agendamento da entrevista com o participante, e outra entrevista com o menino para coletar informações. Como o pai do participante não se encontrava morando no Estado na época da coleta de dados, não foi possível solicitar a presença do mesmo e também não foi possível entrar em contato com ele, pois a mãe em momento algum compartilhou esta informação. Esta pesquisa também não teve auxiliar de pesquisa, tendo somente a presença da autora e coautora para produção do mesmo. Após transcritas as gravações, elas permanecerão guardadas sobre sigilo por um período de aproximadamente 5 anos, sendo descartadas após. Ainda sobre as entrevistas, foram necessários aproximadamente $1 \mathrm{~h}$ de entrevista tanto com a mãe quanto o menino, para coletar dados e retirar dúvidas e informar sobre a pesquisa. Elas não foram feitas a partir de sessões de psicoterapia, pois o menino já se encontrava em atendimento psicológico com outra estagiária da Instituição de Ensino Superior, onde estas entrevistas foram realizadas em um momento a parte dos mesmos.

Salienta-se que a pesquisa não teve potencial gerador de riscos físicos, tampouco psicológicos ao participante. Além disso, nenhum dos procedimentos utilizados ofereceu riscos a dignidade do participante. No entanto, as fragilidades que a pesquisa poderia gerar é: a criança não querer responder e nem se expressar por algum desconforto ao pensar sobre as perguntas contidas na entrevista e na ficha de dados sociodemográficos. Porém os benefícios esperados com o estudo é que a criança pudesse dialogar melhor a respeito da separação dos seus genitores, e o auxílio também a profissionais e estudantes a terem um maior conhecimento sobre o tema pesquisado.

A pesquisa foi revisada e aprovada pelo Comitê de Ética em Pesquisa com Seres Humanos da UFSM em 15/08/2018, com o número de registro Caae 94058318.7.0000.5346.

\section{RESULTADOS E DISCUSSÃO}

Abaixo será apresentado o genograma familiar contendo os dados que foram obtidos através das entrevistas. Com a intenção de preservar a identidade da criança, mãe e demais membros da família, serão utilizados apenas as siglas dos respectivos nomes.

Não será feito análise do genograma, pois a intenção é dar foco para a compreensão da criança acerca do divórcio dos seus genitores. O genograma apenas está inserido no artigo, para facilitar a visualização da família do participante para o leitor. 
Figura 1 - Genograma Familiar do participante.
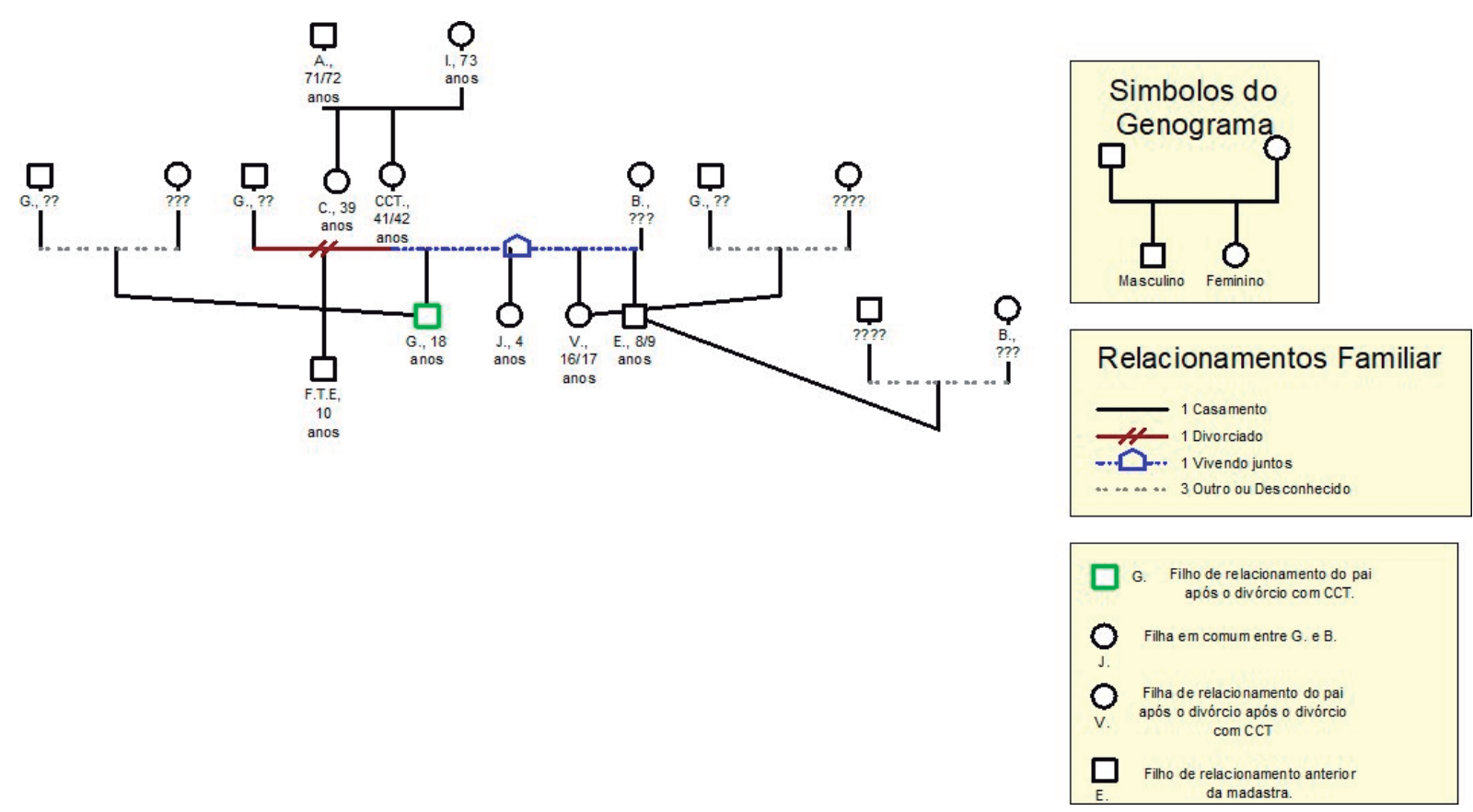

Fonte: Construção da autora.

\section{RESUMO DA HISTÓRIA FAMILIAR}

F.T.E é um menino de 10 anos, que tem seus pais divorciados há no mínimo 7 anos, ou seja, possuía 3 anos quando o evento ocorreu. Nascido no estado de Santa Catarina. Ele, a mãe e o pai na época moravam lá quando ocorreu o divórcio. F.T.E não consegue se lembrar especificamente do divórcio dos seus pais, porém diz se lembrar da troca de casas, e consequentemente de cidade.

Atualmente, a mãe do menino, C.C.T, trabalha em um shopping da cidade de Santa Maria-RS, onde fica nos turnos da manhã, tarde e um pouco da noite. A mesma recentemente recebeu o diagnóstico de câncer de mama.

Hoje, esta mãe conta com a ajuda de sua mãe, I. para conseguir ficar com o seu filho enquanto a mesma está trabalhando. C.C.T e I., mãe e avó respectivamente, moram em um mesmo residencial da cidade de Santa Maria-RS, onde acaba facilitando todo esse processo. Na casa da avó I. moram A. que é o avô do menino, L. que é o primo do mesmo e as vezes a namorada do primo L. que também frequenta o apartamento. F.T.E estuda pela tarde, e então pela manhã fica na casa da avó, sendo assim na saída da escola volta para lá até a mãe buscá-lo após o serviço.

O pai do menino G., continua morando atualmente no estado de Santa Catarina, onde hoje é dono de uma loja de motos da cidade. Este pai atualmente está com B., em um novo relacionamento, onde a mesma tem um filho de um relacionamento anterior, chamado de E. com 8/9 anos aproximadamente. Juntos, G. e B. têm uma filha, J. de 4 anos, identificando assim um novo recasamento de G. 
O pai anteriormente teve outro relacionamento, onde também possui mais dois filhos, que são V. com 16/17 anos aproximadamente, e G. com 18, onde ambas as crianças são cadeirantes e também passam as férias com o pai. Sendo assim, F.T.E mora com a mãe na cidade de Santa Maria-RS, porém passa o Natal com ela e o Ano Novo e o restante de suas férias com seu pai, ou seja, mesmo havendo impedimentos em algumas situações, tenta dividir da melhor forma possível o tempo com seus pais.

\section{RELAÇÕES FAMILIARES}

\section{FAMÍLIA AMPLIADA}

No caso de F.T.E, quando perguntado para ele descrever como era cada membro da família dele e sua relação com os mesmos, ele diz "eu fico mais na casa da vó, porque minha mãe trabalha né, ela trabalha de manhã até de noite...", logo ele continua na seguinte frase "E eu fico mais na vó do que na nossa casa né, é a relação da gente ela é boa, as vezes a gente briga, as vezes todo mundo dá uns grito né.. É de família, mas, a gente consegue... A gente tem uma relação boa...”. Percebeu-se no discurso do menino que o tempo que ele passa na casa da avó é muito satisfatório, porém que há momentos em que todos passam por desacordos de situações do dia-a-dia.

Sabe-se que como influência positiva destacam-se os casos de avós que atuam como mediadores de conflitos e que amortecem as situações de estresse familiar, pois eles auxiliam na resolução problemas vivenciados pelos filhos e netos, onde eles se tornam confidentes e companheiros, fortalecendo a autoestima e independência dos membros da família, moderando a influência negativa que os pais possam exercer sobre seus filhos, ajudando-os, assim, a entenderem melhor as mudanças que ocorrem nas famílias (BAPTISTA; TEODORO, 2009).

Percebe-se que além do menino falar bastante da relação aos gritos com sua avó e tia, F.T.E é muito consciente que isto faz parte da sua família, mas que sua avó não faz por mal, pois traz a fala “Tipo, a vó, a vó tem as vezes que ela quer nosso bem...", mas ressalta que sua relação com a avó, parece ser um pouco conturbada, já que logo após essa fala, ele continua relatando "Mas tem as vezes que ela incomoda...", demonstrando uma contradição na sua fala, que mesmo havendo momentos bons com sua avó, há os momentos ruins incluso, sendo que o mesmo sabe reconhecer ambos.

É possível identificar com os relatos de F.T.E que o mesmo tem uma percepção de mundo muito além da sua idade cronológica, visto pela forma com que o mesmo consegue perceber que mesmo com os momentos ruins, ele gosta da sua família, a ama muito e parece conseguir compreender o quanto esta família tem auxiliado para seu desenvolvimento e maturidade.

Em resumo, percebe-se que esta família ampliada tem sido de extrema ajuda para a mãe C.C.T para que ela possa continuar trabalhando. Ao final, F.T.E ainda traz que não mudaria nada em sua 
família, "Minha família é boa do jeito que ela é. Mesmo com as brigas e tudo, hããã, mesmo com as brigas que dá, as vezes dá bastante briga, ela... A gente se ama bastante e isso que importa."

Há muito tempo a família é reconhecida como uma unidade fundamental da organização social da vida dos seres humanos, livre do padrão particular da vida familiar, das narrativas, dos mitos, das lendas e até mesmo do folclore. Todas as culturas sabem e valorizam o poder das relações familiares como formadoras do caráter da pessoa e como exemplo da ordem moral e política da sociedade (BLOCH; HARARI, 2007).

Percebe-se então que a família assume grande importância para a criança no divórcio dos pais. À medida que, de forma clara e compreensível a decisão do divórcio é comunicada aos filhos, menos fantasias eles criam acerca desta situação e mais chances têm de elaborar o ocorrido, saudáveis emocionalmente. "A forma como pais e familiares transmitem às crianças e adolescentes suas emoções serve para acalmar ou deixar elas mais aflitas" (ASSIS, 2006, p.16).

F.T.E também comentou em breves momentos durante a entrevista sobre a relação com a família paterna, porém nunca se estendeu muito na fala, onde só comenta em relação a avó paterna, quando fica as férias na casa do pai, "Mas as vezes, mais quando a gente tava lá, mais quando a gente ficava na casa da praia da vó né, ela morava perto de uma prainha...", demonstrando um convívio quase nulo, visto que F.T.E não comenta se esta avó liga ou se ambos mantém contato fora do período que ele a visita, constatando assim um relato pobre de investimentos por parte do participante.

\section{NOVOS ARRANJOS FAMILIARES}

Começo o tópico citando que logo no início da entrevista, F.T.E menciona que tem 3 irmãos, “Tudo por parte de pai.". Seus irmãos são: E. filho de relacionamento anterior de B. de 8/9 anos aproximadamente. V. e G. que são filhos apenas de G (pai), com 17/16 e 18 anos respectivamente. E a J. filha de B. com G. de 4 anos.

O vínculo fraterno é então compreendido como resultado de um processo interrelacional, onde ele é construído e definido mediante as trocas estabelecidas entre os irmãos, os quais poderão ou não satisfazer suas diferentes necessidades. O vínculo fraterno pode ser transformado e ressignificado também ao longo da vida, o que revela para nós seu caráter dinâmico e duradouro (OLIVEIRA, 2000).

F.T.E fala de uma forma muito carinhosa de seus irmãos, não havendo preferência por nenhum, e sim demonstra gostar de todos de uma forma muito singela. "A minha irmã que é a J. né de 4 anos, só que os meus outros dois irmãos que são a V. e o G... Eles são dois paraplégicos...”. Assim que cita isso, F.T.E recorda de um momento com seus irmãos na praia, "Mas as vezes, mais quando a gente tava lá, mais quando a gente ficava na casa da praia da vó né, ela morava perto de uma prainha, onde tinha um espaço bem grande, as vezes eles vinham lá e daí a gente... Eu, eu, o R. né que é meu primo, a gente ficava brincando com a cadeira de rodas dele (dos irmãos)... E a V. vinha junto comigo, 
que ela ia bem devagarinho, que ela ia me ensinando como andar de cadeira de rodas..... Ou seja, visto pelo relato parece que F.T.E tem um relacionamento afetivo com seus irmãos.

Com isso, os novos arranjos caracterizam-se por uma maior complexidade de papéis e de organização, o que não significa que no processo de uma família reconstituída seja, obrigatoriamente, conflituoso. Os remanejos são necessários e possíveis graças a flexibilidade das relações presentes no núcleo familiar (GRISARD FILHO, 2003; WAGNER, RIBEIRO, ARTECHE; BORNHOLDT, 1999).

Seguindo com a entrevista, é dado o momento específico para a pergunta sobre a madrasta de F.T.E, onde o menino também não entra em muitos detalhes, pois não soube informar a idade dela, e nem muitas outras características pertinentes sobre a mesma a não ser quando questionado, devido ao pouco convívio.

Quando indagado se o pai apresentou F.T.E a madrasta, ou a nova companheira, ele traz a seguinte fala "Eu não me lembro... Só que eu acho que quando eu cheguei, ela já tava lá.". Logo, ele também diz "Pra mim é normal...", o pai possuir outra família, com outras pessoas. Nota-se diante desta situação que o diálogo entre pai e filho não ocorreu, entende-se através da psicologia o quanto momentos de diálogos e preparação para que novos membros sejam inseridos no contexto familiar devem ser valorizados e no caso de F.T.E o menino relata que não houve essa preparação inicial.

O participante também relata que a irmã mais nova, J. de 4 anos, faz aniversário um dia antes dele. "O legal é que ela faz aniversário 1 dia antes do meu...". Em seguida, entra em detalhes comigo de uma festa de aniversário que houve a princípio para os dois. "Mas um dia ela fez o aniversário né, e no próximo dia já era o meu aniversário, só que como teve o aniversário dela, não fizeram festa pra mim, o pai falou que, eu perguntei 'pai, não vai ter festa pra mim?', dai ele falou que não, porque por causa que a festa da J. era pra nós dois, mas mais foi pra ela... Por causa que eu... Não ganhei nada, mas é... Mas mesmo assim não precisava de nada...".

Ressalta-se novamente a comunicação praticamente inexistente e falha deste pai para com seu filho. Vê-se com a situação que as pessoas que foram na festa no dia não sabiam que era aniversário de F.T.E também, e que nem o pai parece ter reservado algo da festa de aniversário para ele, para que ficasse identificado que era para o mesmo, sendo assim percebe-se que a relação entre pai e filho parece ter ficado um pouco estremecida perante tal situação.

F.T.E relata que para ele, esta situação não gerou nenhum sentimento negativo em relação a irmã, "Não... Eu não senti nada...”, preservando assim a relação fraternal. Identificou-se que o mesmo apresentou uma maturidade no descrever o relato que por mais que tenha demonstrado tristeza, a relação entre irmãos não ficou abalada perante este evento.

É perceptível que F.T.E fala de seus irmãos, de uma forma muito carinhosa e com grande apego a eles. Visto que seus pais estão separados há muito tempo, F.T.E parece ter conseguido se adaptar muito bem a nova família do pai, já que em momento nenhum se refere a todos eles, de uma forma negativa. 


\section{A CRIANÇA PÓS DIVÓRCIO}

\section{(RE)ORGANIZAÇÃO FAMILIAR}

Começo o item com a fala do próprio participante, onde F.T.E relata, durante a entrevista “Eu passo o natal aqui e o ano novo lá.", ou seja, percebe-se que há uma divisão do tempo com os dois genitores, mesmo após tantos anos de divórcio dos seus pais.

F.T.E também relata que o que mais agrada ele sobre seus pais é, "Mas o pai ele é bem legal comigo, ele sempre me leva pros lugar quando ele pode né, por causa que o pai também trabalha até de noite, e...", logo continua, “Que os dois (pai e mãe) eles são bem legais comigo. Eles fazem um monte de coisa por mim.". Percebe-se nesta fala que F.T.E é muito agradecido por seus genitores e pelas coisas que eles fazem pelo menino, mesmo com a distância e do tempo que precisa estar com os dois.

Destaca-se com isso que a parentalidade precisa continuar após a separação, porque por mais que existam ex-maridos e ex-esposas, jamais existirá ex-mãe e ex-pai, pois o vínculo parental é para sempre (GRZYBOWSKI, 2011). Além disso, para a autora a parentalidade implica uma série de responsabilidades essenciais com os filhos, e precisa o tempo todo ser remodelada e adequada no contexto de separação conjugal, porque enquanto pais, o ex-casal precisa compartilhar a tarefa de educar os filhos, abrindo espaço para o que denominamos de coparentalidade.

Durante a entrevista, o participante citou um evento em que ambos os genitores colocaram ele de castigo pois relataram que ele estava ficando "viciado" no notebook, mais tarde quando pergunto a ele se seus pais conversam sobre sua criação, o mesmo relata dizendo que não, e expressa vontade para que os mesmos conversem, “Ah... Acho que sim.”. Com isso e com esta fala, percebe-se que a comunicação entre os genitores de F.T.E é nula, e o menino serve como uma espécie de mediador entre eles.

Considera-se que um pai separado deveria manter um relacionamento com a ex-mulher, já que apenas a relação conjugal acabou, pois a relação é diferente dos laços que unem este homem e esta mulher como pais. O que se sabe é que as características da relação dos ex cônjuges podem atuar como facilitadoras ou dificultadoras desta reorganização (WARPECHOWSKI, 2012). Com isso, podemos relacionar que esse ex casal, G. e C.C.T não possuem nenhum tipo de comunicação, independentemente da situação, ela é inexistente. Isso acaba dificultando até mesmo o acordo entre o ex casal a algumas situações relativas ao próprio filho.

Para Brito (2008) logo após a separação alguns filhos podem exercem a tarefa de transmitir recados, informações já que os pais pós separação mantém uma comunicação quase nula. Estes recados dizem respeito a questões financeiras e ao cotidiano dos próprios filhos. Percebe-se, no entanto que mesmo após a separação, os filhos continuam expostos às brigas.

Com relação aos relatos de F.T.E, a criança assumiu um papel de mediador entre seus genitores, destacando que o mesmo possui uma maturidade elevada para a sua idade, visto que, em muitas situações, 
parece conseguir relatar de uma forma muito madura o divórcio deles e de como o menino tem feito para lidar com adversidades, incluindo a saudade de seu pai, a distância, dentre outros fatores...

Por outro lado, Papalia e Feldman (2006), destacam que as crianças que possuem características pessoais como inteligência facilmente sociável, sem graves problemas de comportamento, e que possuem um senso de controle sobre suas vidas, se apresentam de forma diferenciada e podem lidar melhor tanto com o conflito entre os pais, tanto como o divórcio entre eles. Levando em consideração esta ideia, as autoras perceberam que a criança é um ser capaz de conviver e habituar-se ao divórcio dos pais, de forma com que este seja compreensível para ela e que passe a entender o divórcio de uma maneira diferente, agora, de forma aceitável e já não mais com uma configuração tão dolorosa.

Em síntese, nota-se que o menino consegue fracionar bem seu tempo com os genitores, apesar da distância que é um fator que o impede de ver seu pai com mais frequência. Ressalta-se aqui como a comunicação com os pais de F.T.E é inexistente, sendo um ponto que poderia vir a ser melhorado para o pleno desenvolvimento da criança. Não se sabe o porquê C.C.T e G. não conversam, visto que nem a mãe em entrevista permitiu-se falar sobre o ocorrido, e nem F.T.E não soube explicar o motivo. Podemos destacar também que a criança não é culpada e muito menos tem que ter a responsabilidade por ter que "dividir" seu tempo com os pais.

Para as crianças é melhor ter pais separados e felizes, do que juntos e na presença de brigas, choro e angustia. Nestes casos, a criança pode oscilar atribuindo a si mesma a responsabilidade pelo conflito ou revoltar-se aos pais com situações vivenciadas que geram desconfortos familiares. Desse modo, a crise familiar é sentida pela criança como uma perda, por mais adaptada que ela esteja com a situação, ela vive numa mistura de sentimentos, pois, as crianças são muitos sensíveis, espertas e atentas ao ambiente familiar, e percebem o clima de tensão ou de harmonia que é construído entre os pais (CAMPOS, 2002).

\section{SENTIMENTOS DA CRIANÇA ACERCA DA SEPARAÇÃO}

Sobre a saudade do pai, F.T.E se emociona bastante quando perguntado se ele vê o pai com bastante frequência, se eles se ligam ou mantém o contato, e o menino fala, "A gente parou de se ligar.", e logo em seguida continua, "Mas eu vou ligar pra hoje, pra ele... Porque ontem eu senti muita saudade dele. Quando eu vi uma foto do meu aniversário de 2 ou 3 anos. (...) Que tava ele e a mãe me segurando no colo.".

Perante essa situação, podemos destacar os danos que a não convivência com o pai gera na criança, o mesmo possui uma saudade muito significativa de seu pai, onde a criança acredita ser difícil falar com alguém sobre esses sentimentos, ficando perceptível na fala do menino quando ele diz em diversos momentos da pesquisa que não se sente confortável para falar sobre o assunto, com seus amigos e até mesmo sua mãe. 
Ressalto aqui, que durante a entrevista enquanto foi feita a pergunta de como F.T.E se sentia em relação a separação dos seus pais, o mesmo se sensibilizou também nesta pergunta, trazendo a fala, "Ah...eu, - pigarreio na fala- As vezes eu fico com saudade do pai, dai eu começo a ficar um pouco triste, porque eu queria muito ver ele, (...) Nessas férias de Julho né, que teve, (...) eu fiquei muito triste porque falaram que iam vir me buscar, mas na verdade pensaram que não ia valer a pena, porque ia ser uma semana...Pra mim ia valer a pena, porque pelo menos ia ver o pai, mas daí quando isso aconteceu, eu comecei a chorar, a ficar muito triste...”.

Clareza, liberdade de expressão emocional e resolução colaborativa dos problemas são aspectos que devem compor a comunicação familiar. Eles aparecem por meio de mensagens claras, diretas e específicas entre seus integrantes, no compartilhamento e na exposição dos sentimentos e na postura pró-ativa na resolução de conflitos (GAIDZINSKI, 2014).

Continuando no mesmo tópico, F.T.E relata que não se sente a vontade de falar com alguém quando fica com saudade do seu pai, mas continua ressaltando sobre passar 7 dias com seu pai de férias, “Ah... Eu fico... Eu fico pensando que tipo... Mesmo que fosse só 7 dias né, 1 semana, pra mim do mesmo jeito seria bom eu ver o pai, nem que fosse pra...7 dias, eu já mataria a saudade dele, porque eu ia ver ele, eu ia ficar lá com ele, ia ver minha irmã também.". Trago então a contradição que notei durante as entrevistas realizadas com a mãe e a criança. Onde a mãe diz que existe diálogo com o filho com relação ao divórcio, e o menino relata que não se sente confortável para falar com alguém sobre o mesmo assunto, havendo falha mais uma vez no diálogo entre a criança e um de seus genitores.

Aqui, retomamos ao pensamento de que como a comunicação entre seus pais é nula, isso causa o sentimento de não valorizarem o sentimento da criança perante essa situação, já que era uma vontade de F.T.E visitar seu pai e isso não foi atendido, causou um sentimento de tristeza e sensibilização muito grandes. Visto assim, podemos notar que o vínculo entre pai e filho é muito consolidado, ficando notável que a criança gosta muito de seu pai e dos momentos que passa com ele.

Silva (2005) vai dizer que o afastamento que é provocado pela separação conjugal, que na sua grande maioria, a guarda do filho fica com a mãe, faz com que o entendimento que se tenha em relação a paternidade se fortaleça, sendo que, por vezes, com a saída do homem de casa cria uma possibilidade deste de reconstruir uma ligação afetiva com seus filhos com base em algo que se constrói a cada dia, em cada gesto e em cada situação.

Por isso, nem toda separação conjugal despertará dificuldades ou sentimentos negativos, ela também poderá reverberar nesse fortalecimento dos laços afetivos entre pais e filhos. Diante de uma relação que será construída por um bom vínculo entre ambos, o fato de não morarem juntos poderá contribuir para melhorar a qualidade da relação entre pai e filho (AREND, 2012).

Ainda em relação a saudade do pai, F.T.E traz um sentimento muito singelo, quando fala " $E u$ queria que ele pelo menos... Eles não precisavam estar namorando ou casados, mas pelo menos se ele morasse aqui em Santa Maria, ou eu ainda morasse em Florianópolis...”. E também traz 
expectativas muito grandes, quando traz na fala "Que é onde o pai mora e onde eu nasci, ficaria bom. E eu e a mãe, a gente tá assim pensando em se mudar pra lá de novo...”. Ou seja, esse filho é privado do convívio com seu pai devido à distância, o que não resulta em culpa da criança diante da situação, mas que isso acaba dificultando mais ainda o contato dos dois.

Percebe-se que F.T.E sente muita saudade do seu pai, já que o mesmo mora em outro Estado. Porém deixo novamente aqui a consideração a ser feita: a criança não é responsável pela separação de seus pais, muito menos a culpada pelo processo, pois nota-se que o menino não sabe a história de seus pais, falando que "Não sei. É que eu não sei de como eles se separaram, eu não sei como que aconteceu, eu não sei como que foi a história deles, como que eles se separaram...", logo continua na mesma fala, dizendo "Não... Eu vou esperar mais um tempo pra perguntar...", demonstrando um interesse na história de seus genitores, porém ele mesmo prefere estar mais velho para saber o motivo.

A criança precisa encontrar a liberdade para se expressar, para conversar com cada um de seus pais, assim como estar a par do que está vivenciando. Uma boa comunicação é essencial para todas as famílias, independente do contexto, pois ela fortalece a resiliência de seus membros, facilitando o funcionamento familiar e se torna um instrumento poderoso no divórcio dos pais (WALSH, 2005).

Sendo assim, F.T.E não consegue relatar muitos fatos do divórcio de seus pais, pois era muito novo para se lembrar deste processo, porém consegue falar que diversas vezes se sente triste, com saudade, já que seus genitores moram distantes um do outro, dificultando talvez o processo de visita.

\section{CONCLUSÕES}

O presente relato de pesquisa que teve como objetivo compreender as questões de parentalidade frente à separação conjugal na visão de uma criança. Com isso, buscou-se entender quais sentimentos foram gerados com a separação na mesma, identificando se houveram modificações nas relações parentais após o divórcio, e investigando se houve impacto frente à separação nas relações cotidianas da criança.

Após o estudo de caso ter sido realizado, foi possível notar que o participante tornou-se resiliente quanto ao divórcio de seus pais, ou seja, é bem visível a maturidade apresentada pelo participante quando o assunto é a sua nova configuração familiar, demonstrando entendimento com relação à decisão dos pais. Porém, embora sendo a distância um fator que impede o convívio de F.T.E com um de seus genitores, o menino parece conseguir lidar bem com a situação, mesmo que, em alguns momentos sinta muita saudade de seu pai e fique sensibilizado, o que foi bastante perceptível durante alguns momentos da entrevista e dos relatos apresentados na presente pesquisa.

Ao mesmo tempo, foi possível notar que o participante tem uma percepção de mundo além de sua idade cronológica, ora podendo ser devido a seu convívio na maior parte do tempo com adultos, 
ora pelas vivências na qual foi submetido. Apesar dos desacordos que ele relatou com sua família o menino parece entender que isso pode ser corriqueiro e que eventuais desentendimentos acontecem, e que a família apenas quer o bem dele. Em conclusão, podemos levantar hipóteses que F.T.E é muito consciente do processo de divórcio dos seus pais, mas não se sente pronto ainda para compreender a história que motivou a separação deles.

Um dos pontos na qual é preciso destacar neste estudo de caso, foi a falta de comunicação, ora seja em relação à mãe com o próprio filho, ora em relação ao pai com o filho, e até mesmo entre o ex casal. Destaca-se que a comunicação por inúmeras vezes é inexistente entre o ex casal, o que acaba por dificultar no desenvolvimento pleno de F.T.E.

Sendo assim, sabe-se que o processo de comunicação deveria ficar sob responsabilidade dos adultos, mas neste caso, fica para F.T.E interceder por situações e decisões que deveriam ser tomadas pelos pais. Nota-se que o menino faz o papel de mediador entre os adultos diante de situações cotidianas, porém ressalta-se que ao mesmo tempo o sentimento e a vontade dele não são valorizados perante aos adultos.

Com isso, é possível refletir que a dificuldade existente na comunicação pode ser devido a alguns problemas que ainda não foram resolvidos entre os genitores, podendo estar relacionado a hipóteses no qual isso acontece, pois a mãe apresentou problemas de enfrentar o processo de divórcio com seu ex. marido, verbalizando que o assunto ainda a sensibiliza bastante, o que acarreta na falta de comunicação com o filho sobre o assunto.

Destaca-se neste estudo que a falta da comunicação pode gerar consequências, especialmente no que condiz ao amadurecimento da criança, pois a mesma pode se sentir perdida, sem saber o que fazer quando está com o pai, e consequentemente com a mãe. Sendo assim, os adultos é que deveriam ser a referência do menino no âmbito da tomada de decisões e na comunicação.

Conclui-se que a pesquisa atingiu seus objetivos iniciais, porém aponta que a família precisa investir mais no aspecto da comunicação, para manter as relações sadias com todos os membros da família. Após todo levantamento de dados da pesquisa, foi realizado contato com a mãe para devolução dos resultados após 1 ano das entrevistas, porém não foi possível entrar em contato diretamente com ela pelos números disponibilizados, sendo assim, entrei em contato na casa da mãe e a avó do menino atendeu o mesmo e disse que iria passar a mensagem para dar retorno as pesquisadoras, não foi obtido retorno da mesma até a presente data de publicação deste artigo.

\section{REFERÊNCIAS}

AREND, J. C; SOUZA, K. S; SMEHA, L. A relação entre pai e filho (s) após a separação conjugal. Barbarói, v. 37, p. 7-29, 2012. Disponível em: https://bit.ly/3gDy3fV. Acesso em: 20 jul. 2020. 
ASSIS, S. G; Por que é importante ajudar os filhos a "dar a volta" por cima? Conversando com pais de crianças e adolescentes sobre as dificuldades da vida. Rio de Janeiro: FIOCRUZ, p. 48, 2006. Disponível em: https://bit.ly/3wK7pYs. Acesso em: 23 jul. 2020.

BAPTISTA, M. N; TEODORO M. L. M. (Org.). Psicologia de Família: Teoria, avaliação e intervenções. Artmed Editora, 2009. Disponível em: https://bit.ly/35xVbWU. Acesso em: 23 jul. 2020.

BIASOLI-ALVES, Z. M. M. Pesquisando e intervindo com famílias de camadas sociais diversificadas. In: RINALDI, C.; ALTHOF, I. E; NITSCHKE, R. G. Pesquisando a família: Olhares contemporâneos. Florianópolis, SC: Papa Livros, p. 91-106, 2004.

BLOCH, S.; HARARI, E. Terapia Familiar. In GABBARD, G. O.; BECK, J.S.; HOLMES, J. (Org.). Compêndio de psicoterapia de Oxford. Porto Alegre: Artmed, 2007.

BOLSONI-SILVA, A. T.; VILLAS BOAS, A. C. V. B. A relação ex cônjuge e entre pais e filhos após a separação conjugal. 2009. Disponível em: https://bit.ly/35AW8Oo. Acesso em: 07 abr. 2020.

BRANDÃO, E. P. A interlocução com o direito à luz das práticas psicológicas em Varas de Família. In: BRANDÃO, E. P; GONÇALVES, H. S. Psicologia Jurídica no Brasil. Rio de Janeiro: Editora NAU, 2004.

BRASIL, Diretrizes e Normas para Pesquisa Envolvendo Seres Humanos. Conselho Nacional de Saúde. Ministério da Saúde. Brasília,2012. Disponível em: https://bit.ly/3cUwQ1H. Acesso em: 07 abr. 2020 .

BRITO, L. M. T. Família e separações: perspectivas da psicologia jurídica. In BRITO, L. M. T. Alianças desfeitas, ninhos refeitos: mudanças na família pós-divórcio. Rio de Janeiro: EdUERJ, p. 17-47, 2008.

CAMPOS, R. Separação conjugal e a criança. Rio de Janeiro. 2002. Disponível em: https://bit.ly/ 3q8cGGI. Acesso em: 23 jul. 2020.

CRISTIANE, B. Paternidade e separação conjugal: a perspectiva do pai, 2010. Disponível em: https://bit.ly/3zF0x0a. Acesso em: 20 jul. 2020. 
DANTAS, C. R.; JABLONSKI, B.; CARNEIRO, T.F. Paternidade: considerações sobre a relação pais-filhos após a separação conjugal. Paidéia, Ribeirão Preto, v. 14, n. 29, p. 347-357, 2004. Disponível em: https://bit.ly/3gFdBvq. Acesso em: 20 jul. 2020.

DIAS, M.B. Filhos do afeto: Questões jurídicas. Revista dos Tribunais. 2017.

GAIDZINSKI, C. P; NUERNBERG, D. A resiliência infantil no divórcio dos pais sob o olhar de professores do ensino fundamental. Revista de Ciências Humanas, v. 48.1, p. 20-34, 2014. Disponível em: https://bit.ly/2SIRoDn. Acesso em: 20 jul. 2020.

GIL, A. C. Como elaborar projetos de pesquisa. São Paulo, v. 5, n. 61, p. 176, 2002.

GRISARD FILHO, W. Famílias reconstituídas: Breve introdução ao estudo. In: GROENINGA, G.C; PEREIRA, C.R (Org.). Direito de Família e Psicanálise: Rumo a uma nova epistemologia. Rio de Janeiro: Imago, p. 255-268, 2003.

GRZYBOWSKI, L. S. O envolvimento parental após a separação/divórcio. Porto Alegre: PUCRS, 2007. Disponível em: https://bit.ly/3gDC83E. Acesso em: 20 jul. 2020.

GRZYBOWSKI, L. S; WAGNER, A. Casa do pai, casa da mãe: a coparentalidade após o divórcio. Psicologia: teoria e pesquisa, v. 26.1, p. 77-87, 2010. Disponível em: https://bit.ly/3gMQfCR. Acesso em: 20 jul. 2020.

GRZYBOWSKI, L.S. Ser pai e ser mãe como compartilhar a tarefa educativa após o divórcio? In: WAGNER, A. et al. Desafios psicossociais da família contemporânea. São Paulo: Artmed, 2011.

HACKNER, I.; WAGNER, A.; GRZYBOWSKI.A manutenção da parentalidade frente à ruptura da conjugalidade. Pensando Famílias, v. 10, n. 2, p. 73-86, 2006.

HINTZ, H.C. Espaço relacional na família atual. In: CERVENY, C.M.O. (Org.). Família em movimento. São Paulo: Casa do Psicólogo, 2007.

KRÜGER, L. L. Mediação do divórcio: Pressupostos teóricos para a prática sistêmica. In: ROVINSKI, S. L. R; CRUZ, R. M. (Org.). Psicologia Jurídica: Perspectivas teóricas e processos de intervenção. São Paulo: Vetor, 2009. 
LOBO, C. Parentalidade social, fratrias e relações intergeracionais nas recomposições familiares. Sociologia, Problemas e Práticas, v. 59, p. 45-74, 2009. Disponível em: https://bit.ly/3xG6bNN. Acesso em: 20 jul. 2020.

MARTINS, G. A. Estudo de caso: uma reflexão sobre a aplicabilidade em pesquisa no Brasil. Revista de Contabilidade e Organizações. v.2, n.2, 2008. Disponível em: https://bit.ly/3gR1H2G. Acesso em: 20 jul. 2020.

MINUCHIN, P.; COLAPINTO, J.; MINUCHIN, S. O desafio de trabalhar com famílias de alto risco social: Uma abordagem sistêmica. São Paulo: Roca, 2011.

OLIVEIRA, A. L. Irmãos ao longo da vida: Construindo uma memória compartilhada - compartilhando uma memória construída. Dissertação (Mestrado em Psicologia Clínica) - PUC. São Paulo, 2000. Disponível em: https://bit.ly/3wGuMSG. Acesso em: 20 jul. 2020.

OLIVEIRA, D. et al. Impacto das Configurações Familiares no Desenvolvimento de Crianças e Adolescentes. Interação em Psicologia. Curitiba, v. 12, n. 1, p. 87-98, 2008. Disponível em: https://bit.ly/3d0k1D3. Acesso em: 20 jul. 2020.

OLIVEIRA, N.H.D. Família contemporânea. In: Recomeçar: família, filhos e desafios. São Paulo: Editora UNESP; São Paulo: Cultura Acadêmica, 2009. Disponível em: https://bit.ly/3cYjstk. Acesso em: 08 jul. 2020.

PAPALIA, D. E; OLDS, S.W; FELDMAN, R.D. Desenvolvimento Humano. Porto Alegre: Artmed, 8. ed., p. 888, 2006.

PONCIANO, E. L. T.; CARNEIRO, T. F. Conjugalidade, parentalidade e separação: repercussões no relacionamento pais e filhos (as). Psicologia em estudo, v. 22, n. 2, p. 277-287, 2017. Disponível em: https://bit.ly/3iYsHOa. Acesso em: 20 jul. 2020.

SANTOS, A. F. B. et al. Divórcio: consequências no desenvolvimento emocional dos filhos. Revista Conexão Eletrônica, Três Lagoas, v. 14, n. 1, p. 819-826, 2017. Disponível em: https://bit.ly/3gG3Vke. Acesso em: 20 jul. 2020.

SCHABBEL, C. Relações familiares na separação conjugal: contribuições da mediação. Psicologia: Teoria e prática, v. 7, n. 1, p. 13-20, 2005. Disponível em: https://bit.ly/3xBPdjJ. Acesso em: 20 jul. 2020. 
SIGOLO, S. R. R. L. Favorecendo o desenvolvimento infantil: ênfase nas trocas interativas no contexto familiar. In E. G. Mendes, M. A. Almeida \& L. C. A. Williams (Orgs.). Temas em Educação Especial: avanços recentes. São Carlos: Edufscar, p. 189-195, 2004.

SILVA, E. Z. M. Paternidade ativa na separação conjugal. São Paulo: Juarez de Oliveira, 2. ed., 2005.

TRINDADE, J.; MOLINARI, F. Divórcio: do processo psicológico, do luto e dos efeitos na criança. Revista do Ministério Público do RS, Porto Alegre, n. 70, p. 167-181, 2011. Disponível em: https://bit.ly/ 3iXtCOP. Acesso em: 20 jul. 2020.

WALSH, F. Fortalecendo a Resiliência Familiar. São Paulo: Roca, p. 314, 2005.

WARPECHOWSKI, A.; MOSMANN, C. A experiência da paternidade frente a separação conjugal: sentimentos e percepções. Temas em Psicologia, v. 20.1, p. 247-260, 2012. Disponível em: https://bit.ly/ 35CSfsd. Acesso em: 20 jul. 2020.

YIN, R. K. Estudo de caso: Planejamento e Métodos. Bookman editora, 5. ed., 2015. 
